\title{
RESPONSABILIDADE SOCIAL CORPORATIVA E DESENVOLVIMENTO SUSTENTÁVEL: OLHARES HABERMASIANOS
}

\author{
Isabella Francisca Freitas Gouveia de Vasconcelos ivasconcelos@yahoo.com
}

Professora do Centro Universitário da FEI

Mario Aquino Alves mario.alves@fgv.br

Professor da FGV-EAESP

Yvon Pesqueux yvon.pesqueux@cnam.fr

Coordenador do LIPSOR/CNAM

\section{INTRODUÇÃO}

Práticas e políticas empresariais desenvolvidas sob o termo Responsabilidade Social Corporativa (RSC) vêm ganhando espaço tanto na opinião pública quanto no mundo acadêmico. Agir de maneira socialmente responsável tornou-se um nicho de mercado que pode ser atraente para algumas empresas, embora não para todas, pois é um tipo de decisão que leva em consideração o posicionamento estratégico das empresas (VOGEL, 2005, 2006). Por outro lado, há um forte questionamento sobre as motivações das empresas em suas ações de RSC, suscitando dúvidas sobre as suas verdadeiras intenções e propósitos, bem como quanto aos efeitos dessas mesmas ações (BANERJEE, 2008; CARRIERI e BITTENCOURT, 2005; BORGES, MIRANDA, VALADÃO JR, 2007).

Há uma questão maior e de efeitos mais fortes sobre a sociedade como um todo: garantir às empresas, por ações próprias ou por meio de seus agentes designados, maior poder para influenciar a definição das agendas políticas da sociedade. Himmelstein (1997), em seu estudo sobre a filantropia empresarial estadunidense, demonstrou que empresas financiam determinadas causas para, além de obter o retorno de imagem, influenciar os debates sobre temas específicos defendendo seus interesses diretos e indiretos e suas ideologias. No caso brasileiro, o campo do Terceiro Setor foi um espaço propício para a influência das empresas por meio de suas atividades de RSC (ALVES, 2004).

O debate sobre o papel e atuação das empresas merece, portanto, ser avaliado de maneira mais aprofundada e em contextos mais amplos, de sua ação política na sociedade, não apenas local, mas também global. Neste artigo introdutório ao Fórum de Responsabilidade Social Corporativa e Sustentabilidade da RAE/Transformare, propomos uma abordagem sobre a RSC sob uma dupla perspectiva habermasiana: a da ação comunicativa e a da democracia deliberativa.

\section{RESPONSABILIDADE} SOCIAL CORPORATIVA: A TRAJETÓRIA DE UM CONCEITO

No país berço da literatura sobre
RSC, os EUA, o surgimento da moderna corporação trouxe também preocupações éticas sobre a sua gestão, tanto que, no final do século XIX, surgem os primeiros relatos documentados sobre o questionamento das relações entre a empresa e a sociedade (ACQUIER e AGGERI, 2008). Porém, em 1919, a Suprema Corte do Estado de Michigan, nos EUA, julgou o caso Dogde vs. Ford Motor Company favoravelmente ao pleito dos irmãos Dodge, acionistas minoritários que acusavam Henry Ford de reinvestir na empresa, beneficiando consumidores e empregados à custa dos acionistas. O episódio criou jurisprudência que fortaleceu o paradigma da economia neoclássica da atividade das empresas restrita ao exercício de sua função econômica: maximizar o ganho dos acionistas (HIMMELSTEIN, 1997).

$\mathrm{Na}$ época, as poucas vozes que debatiam a função social da empresa e os limites éticos dos gestores o faziam com base na generalização do modelo de grande empresa de capital aberto e controle acionário disperso (ACQUIER e AGGERI, 2008). Uma exceção foi Chester Barnard, em The Functions of the Executive 
(1938), ao defender que executivos deveriam criar códigos de conduta ética nas empresas e suscitar um clima favorável ao "florescimento de condições morais" na condução dos negócios (GOND e MULLENBACH-SERVAYRE, 2004). Décadas depois, respaldado pela visão da economia neoclássica da teoria da firma, Milton Friedman (1970) sacramentaria a ideia de que a única responsabilidade social da empresa é gerar lucro, reduzindo a responsabilidade dos gestores à maximização dos ganhos dos acionistas.

A partir dos anos 1970, porém, novos autores passaram a questionar a primazia dos interesses dos acionistas sobre a sociedade. Autores como Manne e Wallich (1972), Davis (1973), Stone (1975), Carroll (1979) e Frederick (1987) conferiam às empresas responsabilidades sociais e obrigações que iam além das econômicas, contratuais ou legais. Desse modo, a RSC correspondia à identificação e satisfação dos interesses de todos aqueles que são afetados pelas atividades das empresas (REYNAUD, 2008): funcionários assalariados, consumidores, fornecedores, detentores dos capitais da sociedade, clientes etc., além dos acionistas (stockholders). Em 1978, Emshoff e Freeman (1978 apud GOND e MULLENBACH-SERVAYRE, 2004) resgataram o termo stakeholder de uma publicação de 1963 do Stanford Research Institute (SRI) e o definiram como "qualquer grupo cujo comportamento coletivo pode afetar de modo direto o futuro da organização, mas que não está subordinado ao seu controle direto" (ACQUIER e AGGERI, 2008). Mais tarde, Freeman (1984) formalizaria o "stakeholder model", defendido como uma alternativa àqueles que não concordam com o "sharebolder modet' (BARET, 2006).
No stakeholder model de Freeman, o gestor converte-se em avalista dos interesses de todas as partes interessadas, mesmo sob risco de reduzir o retorno dos acionistas. Assim, a nova missão da organização seria estabelecer uma "governança socialmente responsável que iria além da simples coexistência aceitável entre stakeholders" (BARET, 2006, p. 135). A organização passaria a ter também responsabilidades estendidas, e a RSC seria considerada como corolário de boa gestão, ou seja, de uma gestão estratégica e ética que reconheceria as necessidades de todos os atores que têm um interesse na empresa e que avaliam as consequências dos seus atos (GOND e MULLENBACH-SERVAYRE, 2004). A teoria dos stakeholders questiona a separação entre um mundo econômico - dominado pelo interesse e pelo oportunismo - e um mundo ético marcado pela busca do bem comum e da equidade (DUPUIS, 2008). Mais do que representar um avanço considerável na RSC, os trabalhos de Freeman permitiram identificar o outro, aquele sujeito ou grupo para quem a empresa deve alguma satisfação (LAPRISE, 2005).

Em resposta às demandas da Assembleia Geral das Nações Unidas, publicou-se, em 1987, o Relatório Brundtland, que definiu novas bases para o desenvolvimento, listando as políticas e comportamentos necessários para permitir que o planeta se desenvolva dando igual importância às práticas econômicas, ambientais e sociais. A expressão "desenvolvimento sustentável" (DS) derivou desse relatório, assim como a sua definição: "o desenvolvimento que procura satisfazer as necessidades da geração atual, sem comprometer a capacidade das gerações futuras de satisfazer as suas próprias necessidades" (BRUNDTLAND, 1987).
Para Laprise (2005), o DS tornou-se um conceito de sucesso, pois se tornou o "eixo filosófico popular" do final do século XX e do começo do século XXI. Segundo Laprise (2005), a popularização do DS - sob as suas diferentes formas e rótulos - foi resultado do renascimento do conceito de RSC, constituindo, portanto, um vínculo entre o DS e a RSC. O conceito da RSC, assim, deixa de ser meramente teórico e passa a representar uma postura em que as empresas contribuem voluntariamente para melhorar a sociedade e proteger o meio ambiente, em associação com seus stakebolders. Se o DS teve papel importante nas práticas empresariais ligadas ao meio ambiente (LAPRISE, 2005), associado ao conceito RSC, ajudou a popularizar o uso do Triple Bottom Line (ELKINGTON, 1998) nas corporações.

As práticas de RSC, hoje em dia, fazem parte das principais preocupações dos governos, das populações e também dos gestores de empresas. Com efeito, as práticas de RSC constituem o melhor modo para os diferentes atores agirem numa sociedade globalizada (D'HUMIÈRES, 2010).

\section{RESPONSABILIDADE SOCIAL CORPORATIVA EM UMA DUPLA PERSPECTIVA HABERMASIANA}

Os desdobramentos do conceito de RSC, em especial com a incorporação da dimensão do DS, ampliam a necessidade de analisar as práticas das organizações empresariais quer sob o ponto de vista de suas motivações éticas, quer sob o ponto de vista dos efeitos que essas mesmas 
práticas provocam nos diversos stakebolders. É necessário buscar um fundamento epistemológico sólido o suficiente para dar conta dessas duas dimensões. Assim, parece-nos que os trabalhos do filósofo alemão Jürgen Habermas (1984, 1987a, 1987b, 1996, 1998, 2001) nos campos da ética, da racionalidade e da vida democrática parecem promissores para ajudar nessa tarefa.

Para entender essas duas dimensões, é possível tratar RSC a partir de duas perspectivas habermasianas (SCHERER e PALAZZO, 2007).

A primeira perspectiva, baseada em seus trabalhos anteriores sobre esfera pública (HABERMAS, 1984) e ação comunicativa (HABERMAS, 1987a, 1987b), trataria da avaliação ético-normativa da racionalidade das decisões administrativas por uma racionalidade comunicativa, com base no envolvimento dos stakeholders em debates travados em condições não distorcidas de "discurso ideal" (HABERMAS, 1987a, 1987b, 1984). A apropriação da Teoria da Ação Comunicativa para a administração de empresas reside na tentativa de conciliação relativa com a pluralidade da sociedade e a exigência de uma universalidade afirmada por meio da ética (DEETZ, 1992).

$\mathrm{Na}$ empresa, esse conceito conduz à necessidade não de uma simples tolerância, mas de um debate que pode levar a um acordo que seria símbolo da universalidade de direitos e interesses. O caráter universal desse acordo é conquistado pelo confronto de ideias, não de pessoas. Assim, a importância do discurso, em vez da violência, como base ética seria traduzido como o reconhecimento da negociação, parte essencial da fundação dessa empresa. Empresa e Ética pressupõem a existência de modos de pensamentos diferentes, conflitos possíveis, sustentados por debates criativos e fecundos, produzindo uma verdadeira comunicação. Habermas, nesse momento do desenvolvimento do seu pensamento, reconheceu a importância da comunicação, inclusive na empresa, mas ele relaciona essa comunicação a uma exigência e a uma obrigação de verdade que é a base do seu conceito de racionalidade e que lhe faz rejeitar formas de comunicação puramente estratégicas e instrumentais. É possível existir esse tipo de racionalidade nas empresas, porém em contextos específicos.

A segunda perspectiva, baseada nos seus trabalhos mais recentes sobre democracia e política de Habermas (1996, 1998, 2001), procuraria compreender as ações de RSC em contextos de criação de espaços deliberativos e de globalização. Apesar de a visão econômica ainda ser dominante, nas últimas décadas, por influência da teoria de stakeholders e da aplicação de técnicas a ela relacionadas, muitas empresas, sobretudo multinacionais, passaram a agir em diversas áreas anteriormente exclusivas do setor público. As empresas têm atuado de diversas maneiras na sociedade, participando ou financiando projetos e programas em saúde pública, educação, meio ambiente, direitos humanos etc. (VOGEL, 2005). Além das atividades de financiamento, outra importante função e que dá sinais de expansão é a de buscar influenciar políticas públicas por meio de atividades de advocacy ou lobbying (BRELÀZ e ALVES, 2011). Essa visão abriu portas para uma maior análise sobre o verdadeiro papel das empresas como atores ou agentes políticos.
No atual contexto, a atuação empresarial no cenário político, deve-se, principalmente, à necessidade de as empresas promoverem ambientes autorregulados para conseguirem atuar no mercado (FARIA e GUEDES, 2010). Essa atuação deve-se também à cobrança, seja por meio da regulamentação estatal ou por meio da própria sociedade, para que as empresas assumam as responsabilidades pelas consequências externas de suas práticas. Um exemplo seria a adoção de práticas de RSC. O crescente envolvimento de empresas multinacionais em inúmeras áreas de interesse público não pode ser justificado por ações estritamente direcionadas ao aumento da lucratividade da empresa. A globalização abriu espaço para um papel mais ativo e necessário das empresas, no fornecimento de bens públicos e, ainda, como ator político relevante. Scherer e Palazzo (2011) questionam a visão tradicional de que as empresas são apenas atores econômicos enquanto o governo é um ator político, ou seja, de que às empresas cabe a busca pelos lucros enquanto ao Estado cabe a provisão de bens públicos. Em um novo contexto global, essa divisão de papéis precisa ser revista, entendendo que as empresas, atualmente, possuem um papel político e social.

As empresas, por meio de ações de RSC, vão muito além de apenas cumprirem as expectativas da sociedade, envolvendo-se diretamente em ações de regulação e na produção de bens públicos. Isso significaria adotar um novo conceito politizado de RSC, capaz de agregar esses novos papéis assumidos pelas empresas, transcendendo uma visão econômica, para a qual as 
ações de RSC são puramente voltadas à criação de valor para as empresas no longo prazo. Esse novo conceito politizado de RSC é capaz de adequar-se a um novo contexto global, pós-nacional, marcado por novas relações entre o Estado e a sociedade (HABERMAS, 2001).

Nessa nova perspectiva, a ação política deixa de situar-se apenas no âmbito do Estado e passa a atuar na conjunção do Estado, da sociedade civil e das associações, e a separação entre as esferas política e econômica tende a diminuir. Seguindo essa linha de raciocínio, entre os diversos campos de debate em que se situam as empresas e sua ação política, é na esfera ambiental, nas discussões sobre sustentabilidade e desenvolvimento sustentável que novas práticas e novos debates têm se concentrado nos últimos anos (SCHERER e PALAZZO, 2011; HABERMAS, 1996, 2001).

\section{APRESENTAÇÃO DOS ARTIGOS DO FÓRUM TRANSFORMARE}

Os artigos que compõem esse fórum foram selecionados entre os 29 artigos apresentados no Seminário "Organizações Inovadoras Sustentáveis" do Grupo Transformare, realizado no dia 21 de março de 2011, no Centro Universitário da FEI, na cidade de São Paulo.

O artigo "Gifted: the monolingualism of corporate social responsibility" traz uma avaliação crítica das narrativas de sucesso de RSC com base em um caso no Senegal, mostrando a reprodução de uma lógica neocolonial nas práticas de RSC em países em desenvolvimento, apontando para a necessidade de se incorporarem as vozes locais a esses discursos. O artigo "Logística reversa: como as empresas comunicam o descarte de baterias e celulares?" traçou um diagnóstico da comunicação de programas de logística reversa de empresas fabricantes de celulares atuantes no Brasil, à luz dos princípios da Comunicação Integrada de Marketing. Seus resultados mostram o quanto a situação de discurso ideal está distorcida pela falta de efetiva participação dos clientes/usuários no processo de logística reversa. O artigo "Adoção da certificação LEED em meios de hospedagem: esverdeando a hotelaria?" trata da adoção de práticas sustentáveis e internacionalmente acreditadas na construção e reforma dos meios hoteleiros brasileiros, em especial diante do cenário dos grandes eventos programados para os anos de 2014 e 2016. Aqui se verifica como o processo de autorregulação do setor internacional de construção civil antecipa demandas que poderiam vir de outros setores da sociedade. Por fim, o artigo "Gestão e práticas socialmente responsáveis na cooperação agrícola" mostra os limites da teoria de stakeholders, propondo um modelo de decisão baseado na tensão dialética, que associa os diversos stakeholders, com base em estudos de cooperação agrícola na França.

Assim, ao seu modo, cada um dos artigos agrega significativas contribuições para um pensar sobre RSC e DS com base em premissas habermasianas sobre a qualidade ética da comunicação e a necessidade da criação de es- paços democráticos deliberativos onde as vozes possam ser, de fato, ouvidas.

\section{REFERÊNCIAS}

ACQUIER, A; AGGERI, F. Une genealogie de la pensée manageriale sur la SER. Revue Française de Gestion, v.38/180, p. 131-157, 2008.

ALVES, M. A. O conceito de sociedade civil: em busca de uma repolitização. Organização e Sociedade, v. 11, Edição Especial, p. 141-154, 2004.

BANERJEE, S. B. Corporate social responsibility: the good, the bad and the ugly. Critical Sociology, v. 34, n. 1, p. 51-79, 2008.

BARET, P. L'évaluation contingente de la Performance globale des entreprises: une méthode pour fonder un management sociétalement responsable? In: Rose, J-J. (Ed). Responsabilité sociale de l'entreprise, pour un nouveau contrat social. Bruxelles: De Boeck \& Larcier, 2006. p. 135-152.

BORGES, J. F; MIRANDA, F; VALADÃO JR., V. M. O discurso das fundações corporativas: caminhos de uma "nova" filantropia? RAE-Revista de Administração de Empresas, v. 47, n. 4, p. 101-115, 2007.

BRELÀZ, G. DE; ALVES, M. Deliberative democracy and advocacy: lessons from a comparative perspective. $\mathrm{Ca}$ nadian Journal of the Administrative Sciences, v. 28, n.2, p. 202-216, 2011.

BRUNDTLAND, G. H. Our common future: report of the world commission on environment and development. New York: Oxford University, 1987. 
CARRIERI, A; BITTENCOURT, E. Responsabilidade social: ideologia, poder e discurso na lógica empresarial. $R A E-$ -Revista de Administração de Empresas, v. 45, Edição Especial, p. 10-22, 2005.

CARROLL, A. B. A three-dimensional conceptual model of corporate social performance. Academy of Management Review, v.4, n.4, p. 497-505, 1979.

DAVIS, $\mathrm{K}$. The case for and against business assumption of social responsibilities. The Academy of Management Journal, v. 16, n. 2, p. 312-322, 1973.

DEETZ, S. Democracy in an age of corporate colonization: developments in communication and the politics of everyday life. Albany: SUNY, 1992

D'HUMIÈRES, P. Le développement durable va-t-il tuer le capitalisme? Paris: Maxima, 2010.

DUPUIS, J. C. La RSE, de la gouvernance de la firme à La gouvernance de reseau. Revue Française de Gestion, v.38/180, p. 159-175, 2008.

ELKINGTON, J. Cannibals with forks: the triple bottom line of twenty first century business. Vancouver: New Society, 1998.

EMSHOFF, J. R; FREEMAN, R. F. Stakebolder management. Working paper from the Wharton Applied Research Center, 1978.

FARIA, A; GUEDES, A. L. A critical analysis of corporate social responsibility as international strategy. In: Enanpad, 2010, Rio de Janeiro. Anais, Rio de Janeiro: ANPAD, 2010.

FREDERICK, W. C. Theories of corporate social performance. In: Sethi, S. p; Falbe, C. M. (Eds). Business and society. Lexington: Lexington Books, 1987.
FREEMAN, R. E. Strategic management: a stakeholder approach. Boston: Pitman, 1984.

FRIEDMAN, M. The social responsibility of business is to increase profits. New York Times Magazine, New York, p. 32-33, 122, 126, 13.09.1970.

GOND, J. P; Mullenbach-Servayre, A. Les fondements théoriques de la responsabilité societal d'enterprises. Revue des Sciences de Gestion, v.205, p. 93-116, 2004

HABERMAS, J. Mudança estrutural da esfera pública. Rio de Janeiro: Tempo Brasileiro, 1984.

HABERMAS, J. Teoria de la acción comunicativa: racionalidad de la acción y racionalización social. Madrid: Taurus, 1987a. tomo 1.

HABERMAS, J. Teoria de la acción comunicativa: crítica de la razón funcionalista. Madrid: Taurus, 1987b. tomo 2.

HABERMAS, J. Between facts and norms: contributions to a discourse theory of Law and democracy. Cambridge: Polity, 1996.

HABERMAS, J. Three normative models of democracy. In: Habermas, J. The inclusion of the other. Cambridge: MIT,1998. p. 239-252.

HABERMAS, J. The postnational constellation. Cambridge: MIT, 2001.

HIMMELSTEIN, J. Looking good and doing good: corporate philanthropy and corporate power. Indiana: Indiana University, 1997.

LAPRISE, P. La multinationale du pétrole Shell et le développement durable: perspectives du concept de responsabilité sociale et environne- mentale de l'entreprise, Le développement durable: Quels projets, quels outils, quelle formation?, Actes de l'Organisation internationale de la francophonie, n.6, p. 233-24, 2005.

MANNE, H. WALLICH, H. Social responsibility of business. Washington, DC: American Enterprise Institute for Public Policy Research, 1972.

REYNAUD, E. La responsabilité sociale de l'entreprise à l'épreuve de l'Europe, Revue Française de Gestion, v.38/180, p. 109-130, 2008.

SCHERER, A. G; PALAZZO, G. Toward a political conception of corporate responsibility: business and society seen from a Habermasian perspective. Academy of Management Review, v. 32,, n.4, p. 1096-120, 2007.

SCHERER, A. G; Palazzo, G. The new political role of business in a globalized world: a review of a new perspective on CSR and its implications for the firm, governance and democracy. Journal of Management Studies, v.48, n.4, p. 899-931, 2011

STONE, C. D. Where the law ends. New York: Harper \& Row, 1975.

VOGEL, D. J. Is there a market for virtue? The business case for corporate social responsibility. California Management Review, v. 47, n. 4, p. 19-45, 2005.

VOGEL, D. J. The market for virtue: the potential and limits of corporate social responsibility. New York: Brookings Institution, 2006. 